Atmos. Chem. Phys. Discuss., 7, 10179-10203, 2007

www.atmos-chem-phys-discuss.net/7/10179/2007/

(C) Author(s) 2007. This work is licensed

under a Creative Commons License.

Lidar measurements of Asian dust

T. Sakai et al.

\title{
Multiwavelength and polarization lidar measurements of Asian dust layers over Tsukuba, Japan: a case study
}

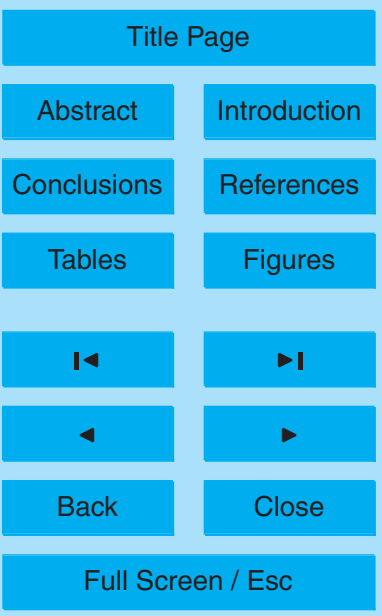

Printer-friendly Version

Interactive Discussion 


\section{Abstract}

Elastic and polarization lidar was used to measure the vertical profiles of aerosol backscattering coefficients at wavelengths of $355,532,735$, and $1064 \mathrm{~nm}$, and the depolarization ratio at $532 \mathrm{~nm}$ in order to study the aerosol properties in the free tro5 posphere over Tsukuba, Japan, in 2006. An elevated dust layer was observed at altitudes between 3 and $8.5 \mathrm{~km}$ on 1 April during the Asian dust period. The wavelength exponents of the aerosol backscattering coefficient $(k)$ were -0.1 to 0.5 , and the depolarization ratio $\left(\delta_{p}\right)$ was $25 \%$ for the dust layer, suggesting the predominance of supermicrometer-sized (coarse mode) nonspherical particles. An aerosol layer observed at altitudes between 1.5 and $5 \mathrm{~km}$ on 19 October during the less-dust period exhibited the values of $k=1.0$ to 1.6 and $\delta_{p}=1$ to $13 \%$, suggesting the predominance of submicrometer-sized (fine mode) particles. In those layers, the values of $k$ and $\delta_{p}$ varied with height; they were also negatively correlated, suggesting that the proportion of the coarse nonspherical particles to total particles varied. The particle size distributions estimated from the observed values and the theoretical computation revealed number mode radii of $0.3 \mu \mathrm{m}$ for the coarse mode and $0.1 \mu \mathrm{m}$ for the fine mode, assuming bimodal distribution. These results were consistent with those obtained from the sky-radiometer measurements, although they revealed another mode in the larger radius. The column volume concentration derived from the lidar was $48 \%$ lower than that derived from the sky-radiometer on 1 April and 16\% lower on 19 October. The optical thickness derived from the lidar was $12 \%$ lower than that obtained from the skyradiometer on 1 April and $29 \%$ higher on 19 October. Further case study is necessary to validate the method for estimating aerosol properties based on the lidar measurement.

Lidar measurements of Asian dust

T. Sakai et al.

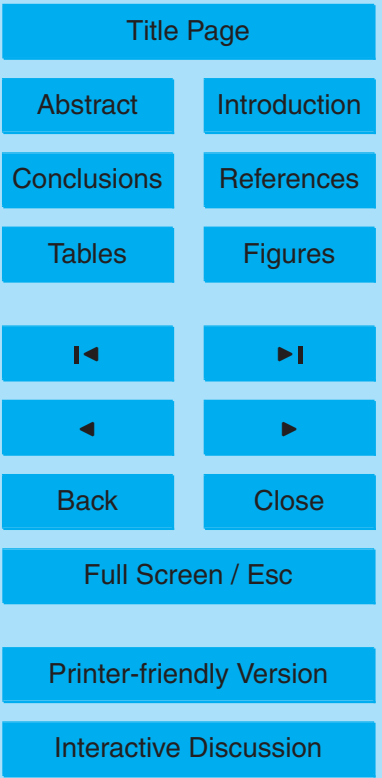




\section{Introduction}

Mineral dust particles that originate from the arid and semi-arid lands of the Asian Continent (Asian dust) are often transported and spread over East Asia and the North Pacific, chiefly during the spring season (Iwasaka et al., 1988; Duce, 1995). The num5 ber of studies and programs focusing on the Asian dust has grown over the past few decades as the importance of regional climate and global biogeochemical cycles has become increasingly apparent (Huebert et al., 2003; Arimoto et al., 2006; Mikami et al., 2006). The dust can affect the Earth's radiation balance by scattering and absorbing solar and terrestrial radiation (Aoki et al., 2005; Shi et al., 2005), and it can affect cloud properties by acting as cloud condensation nuclei and ice nuclei (e.g. Isono et al., 1959; Yamagata et al., 2004).

The impact of dust on the climate critically depends on particle properties such as number concentration and size distribution, shape, chemical composition, and vertical distribution (e.g. Liao and Seinfeld, 1998; Quijano et al., 2000). However, these

15 properties have not been adequately researched, particularly in the free troposphere, because of difficulties in measurement. Lidar is a useful tool for measuring the vertical profiles of the aerosol optical properties. Multiwavelength and Raman lidar measurements provide the aerosol optical properties that can be used for estimating particle size distribution and the refractive index (e.g. Müller, 1999, 2000; Veselovskii et al., 2005). The polarization lidar measurement provides the particle shape and phase (Sassen, 2000). However, few studies have used multiwavelength and polarization data for estimating the aerosol properties.

This paper provides a case study of the multiwavelength and polarization lidar measurement of the aerosol optical properties in the free troposphere over Tsukuba, Japan. wavelength dependence of the backscattering coefficients and the depolarization ratio. Based on the results of the measurement and the theoretical computation of the aerosol optical properties, we estimated the fraction of fine and coarse particles in the

7, 10179-10203, 2007

\section{Lidar measurements} of Asian dust

T. Sakai et al.

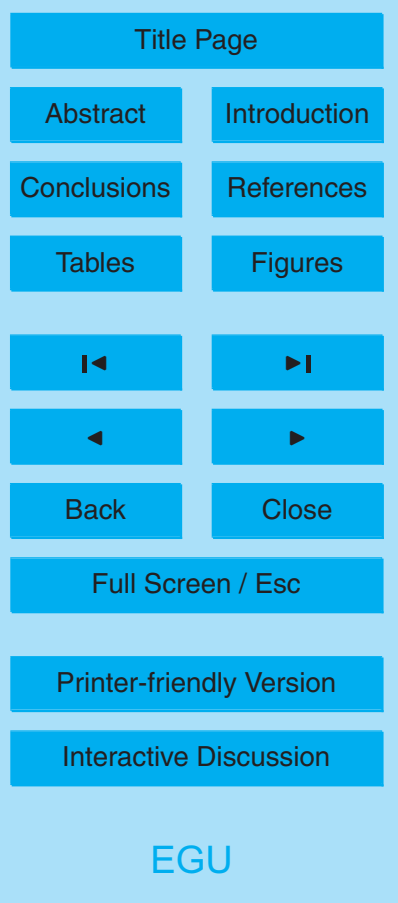


backscattering coefficient and the size distribution. The estimated size distributions were compared with those obtained from the sky-radiometer measurement.

ACPD

7, 10179-10203, 2007

\section{Measurements}

Multiple wavelength and polarization lidar measurements were carried out over 5 Tsukuba $\left(36.0^{\circ} \mathrm{N}, 140.1^{\circ} \mathrm{E}\right)$, which is located $60 \mathrm{~km}$ northeast of Tokyo. The characteristics of the lidar are presented in Table 1. The multiwavelength lidar transmits laser pulses at wavelengths of $355 \mathrm{~nm}, 532 \mathrm{~nm}, 735 \mathrm{~nm}$, and $1064 \mathrm{~nm}$ by use of three laser sources: 1) Nd:YAG laser that transmits laser pulses with a repetition rate of $20 \mathrm{~Hz}$ at $355 \mathrm{~nm}$ with a pulse energy of $80 \mathrm{~mJ}$, and $532 \mathrm{~nm}$ with a pulse energy of $40 \mathrm{~mJ}$; 10 2) Nd:YAG laser that transmits pulses at $1064 \mathrm{~nm}$ with $550 \mathrm{~mJ} /$ pulse at $20 \mathrm{~Hz}$; and 3) $\mathrm{Nd}$ :YAG pumped-dye laser that transmits pulses at $735 \mathrm{~nm}$ with a $16 \mathrm{~mJ} / \mathrm{pulse}$ at $10 \mathrm{~Hz}$. The light backscattered from atmospheric molecules and particles at wavelengths of $355 \mathrm{~nm}, 532 \mathrm{~nm}$, and $1064 \mathrm{~nm}$ is collected by using a telescope with a diameter of $50 \mathrm{~cm}$ and a $3.0 \mathrm{mrad}$ field of view (FOV). The light backscattered at a wavelength 15 of $735 \mathrm{~nm}$ is collected by using a telescope with a diameter of $35 \mathrm{~cm}$ and a FOV of $2.2 \mathrm{mrad}$. The polarization lidar transmits laser pulses at $532 \mathrm{~nm}$ with $300 \mathrm{~mJ} /$ pulse and $10 \mathrm{~Hz}$. The two orthogonal components of the linearly polarized elastic backscattering at $532 \mathrm{~nm}$ are collected with telescopes with a diameter of $20 \mathrm{~cm}$ (FOV of $3.0 \mathrm{mrad}$ ) and $40 \mathrm{~cm}$ (FOV of $2.0 \mathrm{mrad}$ ). The geometrical configurations of the lidar are in biaxial except for the $20-\mathrm{cm}$ telescope of the polarization lidar, which is coaxial. The lowest altitude of the measurement where the laser beam fully overlaps with receiver's FOV is $1.45 \mathrm{~km}$ for the multiwavelength lidar and $0.1 \mathrm{~km}$ for the polarization lidar. The collected light is detected with photomultiplier tubes (PMTs) that are operated in photon counting (PC) mode and analog-to-digital conversion (A/D) using transient recorders 25 (Licel $\mathrm{GbR}$ ) with resolutions of $7.5 \mathrm{~m}$ in the vertical direction, and 1.5 or $3 \mathrm{~min}$ in time. We use PC data above an altitude of $2 \mathrm{~km}$ and $A / D$ data below that altitude. The A/D data are connected to $\mathrm{PC}$ data, multiplying a constant that is obtained by dividing the

\section{Lidar measurements} of Asian dust

T. Sakai et al.

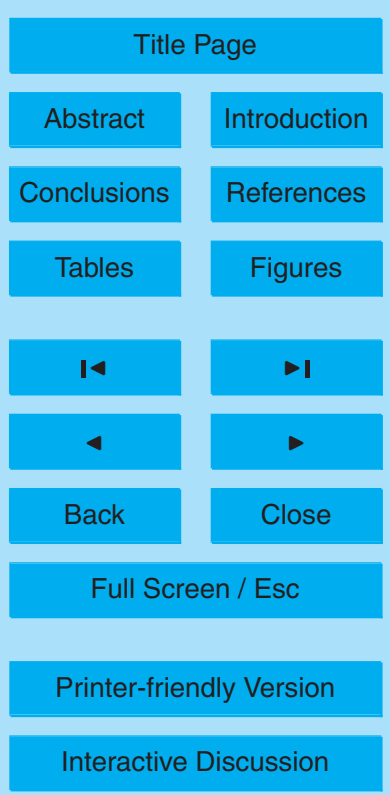

\section{2}


photon count by analog voltage at the height point of the connection.

The quantities obtainable with the multiwavelength lidar are the backscattering ratio $(R)$ and the particle backscattering coefficients $\left(\beta_{p}\right)$ at $355 \mathrm{~nm}, 532 \mathrm{~nm}, 735 \mathrm{~nm}$, and $1064 \mathrm{~nm}$. The value of $R$ is proportional to the aerosol mixing ratio, and that of $\beta_{p}$ is 5 proportional to the concentration, assuming that the aerosol size distribution and the backscattering efficiency remain constant. To calculate these values, we used the iterative method (Fernald et al., 1972; Ismail et al., 1998). In the calculation, we used the height-dependent particle extinction-to-backscatter ratios (lidar ratios, $S_{p}$ ) that were estimated from the particle depolarization ratios. The estimation method is described 10 in Sect. 4. The backscatter signals were calibrated at altitudes of 10 to $15 \mathrm{~km}$, assuming that the $R$ was 1.01 at a wavelength of $355 \mathrm{~nm}, 1.03$ at a wavelength of $532 \mathrm{~nm}$, 1.09 at a wavelength of $735 \mathrm{~nm}$, and 1.27 at a wavelength of $1064 \mathrm{~nm}$, based on the observations at midlatitude (Russell et al., 1979, 1982) and the wavelength dependence of the backscattering coefficient for the continental aerosol model proposed by 15 Ackermann (1998). The molecular backscattering and extinction coefficients were calculated from the atmospheric temperature and pressure data that were obtained with the radiosondes launched $250 \mathrm{~m}$ northeast of the lidar at 20:30 Japan standard time (JST). The vertical resolution of the analyzed data was reduced to $150 \mathrm{~m}$ to improve the signal-to-noise ratio. The uncertainty in the lidar-derived quantities was estimated using Poisson statistics for the observed photon counts.

We calculated the wavelength exponents $(k)$ of the aerosol backscattering coefficient between the four wavelengths ( 355 to $532 \mathrm{~nm}, 532$ to $735 \mathrm{~nm}$, and 532 to $1064 \mathrm{~nm}$ ), assuming the relation $\beta_{p}(\lambda) \propto \lambda^{-k}$. This value was negatively correlated with the mean particle size; it was higher for the smaller particles and lower for the larger particles (e.g.

$25 k \sim 1.5$ for the submicrometer-sized particles and $k \sim 0$ for the supermicrometer-sized particles). We noted that the measured values of $\beta_{p}$ at $1064 \mathrm{~nm}$ had large uncertainty in this study because of the low signal intensity at $1064 \mathrm{~nm}$ at the calibration height. The measurement uncertainties in $\beta_{p}$ were on average $25 \%$ at $355 \mathrm{~nm}, 50 \%$ at $532 \mathrm{~nm}$, $6 \%$ at $735 \mathrm{~nm}$, and over $50 \%$ at $1064 \mathrm{~nm}$ for the studied altitude ranges.

\section{Lidar measurements of Asian dust}

T. Sakai et al.

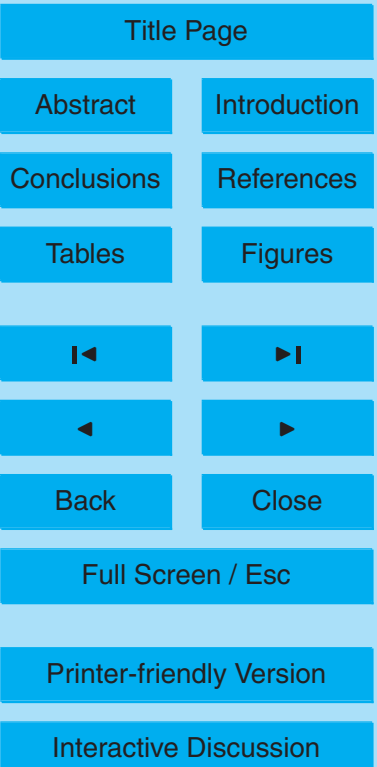

10183 
The quantities obtainable with the polarization lidar are $\beta_{p}$ and the particle linear depolarization ratio $\left(\delta_{p}\right)$ at $532 \mathrm{~nm}$, defined by the ratio of the perpendicular to the total components in $\beta_{p}$ with respect to the polarization plane of the emitted laser light. This value is a measure of the particles' nonsphericity if they are comparable 5 to or larger than the measurement wavelength (e.g. Mishchenko and Sassen, 1998). For example, mineral dust usually has high $\delta_{p}$ values $(>10 \%)$ because it is mostly supermicrometer-sized and nonspherical (Okada et al., 2001). In contrast, spherical particles (e.g. droplets) and submicrometer-sized particles have low $\delta_{p}$ values $(<10 \%)$.

\section{Results}

\subsection{Case on 1 April 2006: Asian dust layer}

Figure 1a presents the vertical distributions of $R, k$, and $\delta_{p}$ that were obtained from 00:01 to 05:03 JST on 1 April 2006. High values of $R$ exceeding 1.5 at $532 \mathrm{~nm}$ were obtained at altitudes between 3.0 and $8.5 \mathrm{~km}$, with a peak value of 2.45 at an altitude of $3.8 \mathrm{~km}$. The optical thickness was estimated to be 0.27 at $532 \mathrm{~nm}$ for this altitude range. The values of $k$ were low, ranging from -0.1 to 0.5 (thin lines in the right panel of Fig. 1a), suggesting that supermicrometer-sized (coarse) particles were predominant. The values of $\delta_{p}$ were as high as $25 \%$ (thick solid line in the right panel of Fig. 1a), indicating that coarse nonspherical particles were predominant. It should be noted that the values of $\delta_{p}$ and $k$ varied with height, and they were negatively correlated (see also Fig. 3). These results suggested that the fraction of coarse nonspherical particles that have higher $\delta_{p}$ and lower $k$ values than those of the fine particles varied with height. This is discussed further in Sect. 4. The coarse nonspherical particles were probably mineral dust particles originating from the arid or semi-arid lands of the Asian continent: back trajectory analysis revealed that the air parcels had been transported over the arid and semi-arid lands of the Asian continent and over the northern part of the Taklimakan Desert three days earlier (Fig. 2a). Details of the method for

Lidar measurements of Asian dust

T. Sakai et al.

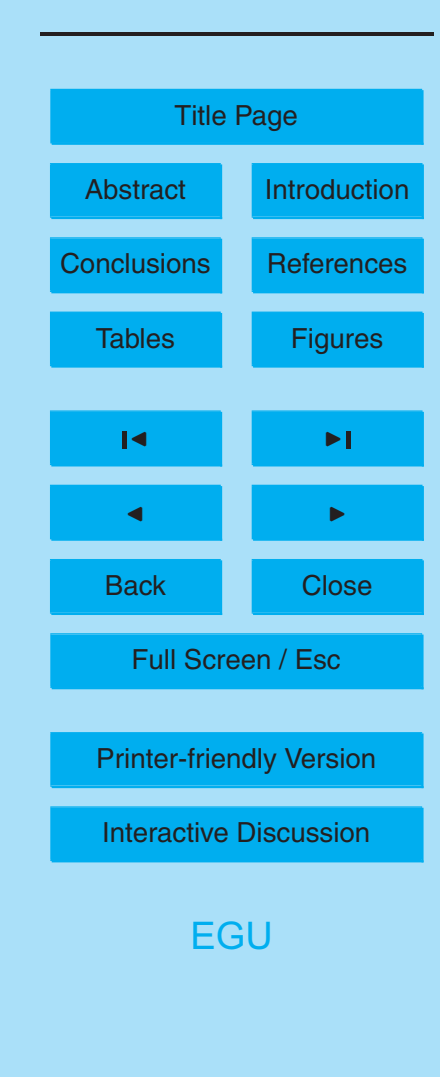


computing the trajectory are given by Sakai et al. (2000). The reasons why we calculated many trajectories located around the lidar site ( 25 points in steps of 0.5 degrees for longitude and latitude) are to consider the possibility of the mixing of different air masses that had passed over the source areas as well as to reduce the uncertainty of

5 the trajectory that can be arisen from the coarse resolution of the meteorological data (1.25 degrees for longitude and latitude) used in the computation. In addition to the trajectory analysis, the aerosol transport model of Navy Aerosol Analysis and Prediction System (NAAPS) also predicted the presence of dust with a mass concentration of 15 to $50 \mu \mathrm{gm}^{-3}$ between 2 and $7 \mathrm{~km}$ in height and sulphates with $1-2 \mu \mathrm{gm}^{-3}$ be10 tween 2 and $3 \mathrm{~km}$ over the lidar site (http://www.nrlmry.navy.mil/aerosol_web/globaer/ ops_01/tsukub/200604/2006032700_2006040100_tsukub.gif). For comparison of the optical properties of the Asian dust, Murayama et al. (2004) observed $k$ of 0.3 to 1.2 at 355 to $532 \mathrm{~nm}$ and $\delta_{p}$ of $18 \%$ at altitudes between 3 and $5 \mathrm{~km}$ over Tokyo during the Asian dust period. Sugimoto and Lee (2006) observed $k \sim 0.5$ at 532 to $1064 \mathrm{~nm}$ 15 and $\delta_{p} \sim 10 \%$ at an altitude of $2 \mathrm{~km}$ for the Asian dust layer over Korea. Our measured values were a little lower for $k(-0.1$ to 0.5$)$ and higher for $\delta_{p}(25 \%)$ than their reported values. This difference was possibly due to the higher fraction of coarse particles in the dust layer that we measured. Ansmann et al. (2002) observed $k$ ranging from -0.5 to 0 at 355 to $532 \mathrm{~nm}$ and $\delta_{p}$ ranging from $10 \%$ to $20 \%$ at altitudes between 1 and $205 \mathrm{~km}$ for the Saharan dust layers over Europe. These values were a little lower than our results, possibly due to the differences in the fraction of coarse particles and the optical properties between the Saharan dust and Asian dust over the remote sites.

\subsection{Case on 19 October: fine particle layer}

Figure $1 \mathrm{~b}$ plots the vertical profiles obtained during the less-dust period for 02:01 to 25 06:45 JST on 19 October 2006. The profile of $R$ indicated peak values of 1.3 at an altitude of $4.3 \mathrm{~km}$, and 1.9 at $2 \mathrm{~km}$ at $532 \mathrm{~nm}$. The optical thickness was estimated to be 0.09 at $532 \mathrm{~nm}$ between 1.45 and $4.7 \mathrm{~km}$. The values of $k$ ranged from 1.0 to $1.6 \mathrm{in}$ those regions, suggesting that submicrometer-sized (fine) particles were predominant.

\section{Lidar measurements} of Asian dust

T. Sakai et al.

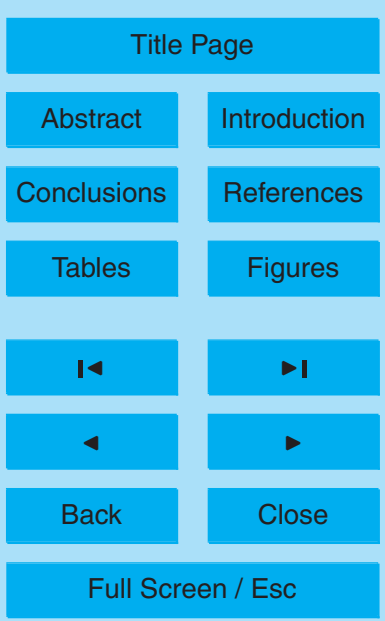

Printer-friendly Version

Interactive Discussion 
The values of $\delta_{p}$ were 1 to $13 \%$, indicating that spherical and/or small (compared with the laser wavelength of $532 \mathrm{~nm}$ ) particles were predominant. It should again be noted that $\delta_{p}$ and $k$ were negatively correlated (Figs. 1 and 3). Clustered backward trajectory analysis revealed that the majority of the air parcels for that altitude region had passed 5 over the industrial regions of the coastal area in China ( 30 to $35^{\circ} \mathrm{N}, 105$ to $120^{\circ} \mathrm{E}$ ), and two parcels had passed over the Taklimakan Desert regions (Fig. 2b). The NAAPS model predicted the presence of a relatively small amount of dust (15 to $25 \mu \mathrm{gm}^{-3}$ ) and sulphates ( 1 to $2 \mu \mathrm{gm}^{-3}$ ) below $4 \mathrm{~km}$ over the lidar site. These results suggested that the Asian dust and sulphates were both present in the aerosol layers measured 10 with the lidar.

\section{Estimation of particle size distribution}

We estimated the particle size distributions of the aerosol layers measured with the lidar by comparison with an aerosol model based on the results of the airborne measurements in the free troposphere near the lidar site (Takamura et al., 1990; Matsuki et al., 15 2003; Sakai et al., 2003; Murayama et al., 2004). The model assumes that the optically effective aerosols were composed primarily of two components: submicrometer-sized ammonium bisulphates in the fine mode and supermicrometer-sized mineral dust in the coarse mode. In the calculation of the optical properties of these particles, the sulphate particles were assumed to be spherical droplets with a refractive index of $1.46+0 \mathrm{i}$ 20 (Tang and Munkelwitz, 1994) and a lognormal size distribution with a geometric standard deviation $\left(\sigma_{g}\right)$ of 1.66 (Sakai et al., 2003). The dust particles were assumed to be triaxial spheroids with a length-to-width ratio of 1.4 and a height-to-width ratio ranging from 0.2 to 1.0, based on the morphological study of the Asian dust by Okada et al. (2001). The refractive index of 1.5+0.001i (Aoki et al., 2005; Kalashnikova and

25 Sokolik, 2004; Arimoto et al., 2006) and a lognormal distribution with $\sigma_{g}=2.0$ (Sokolik and Toon, 1999) were assumed for this particle mode. To compute the aerosol optical properties, we used the Mie code (Bohren and Huffman, 1983) for the fine mode and

Lidar measurements of Asian dust

T. Sakai et al.

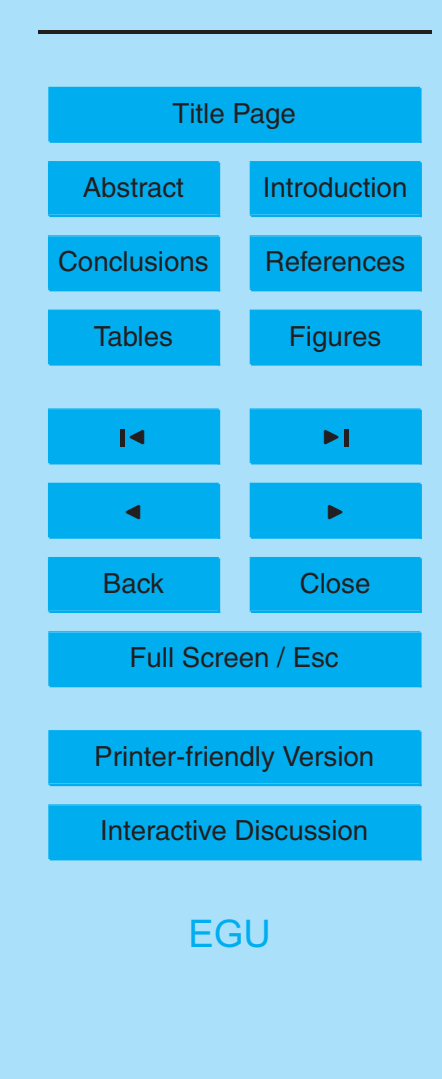


the combined field integration (CFIE) method (Mano, 2000) for the coarse mode. The geometric number mean radii $\left(r_{g}^{N}\right)$ of the two modes were determined in an effort to minimize the difference between the computed values of $k$ and $\delta_{p}$ and those obtained with the lidar by varying $r_{g}^{N}$ as described below.

5 To interpret the observed aerosol optical properties, we expressed the aerosol backscattering coefficient observed with the lidar $\left(\beta_{\text {obs }}\right)$ by

$\beta_{\text {obs }}=\beta_{f}+\beta_{c}$,

where the subscript $f$ refers to the fine mode particles, and $c$ refers to the coarse mode particles. If we define the fraction of $\beta$ of the coarse mode particles in total (fine + coarse) particles by

$f_{c}=\frac{\beta_{c}}{\beta_{f}+\beta_{c}}=\frac{\beta_{c}}{\beta_{\text {obs }}}$,

then the wavelength exponent of the backscattering coefficient observed with the lidar $\left(k_{\text {obs }}\right)$ is expressed by

$\left(\frac{\lambda_{2}}{\lambda_{1}}\right)^{-k_{\mathrm{obs}}}=\left(1-f_{c}\right)\left(\frac{\lambda_{2}}{\lambda_{1}}\right)^{-k_{f}}+f_{c}\left(\frac{\lambda_{2}}{\lambda_{1}}\right)^{-k_{c}}$,

15 where $\lambda_{1}=532 \mathrm{~nm}$ and $\lambda_{2}=355,735$, or $1064 \mathrm{~nm}$. The particle depolarization ratio observed with the lidar $\left(\delta_{\text {obs }}\right)$ is expressed by

$\delta_{\text {obs }}=\left(1-f_{c}\right) \delta_{f}+f_{c} \delta_{c}$

To determine $k_{f}, k_{c}$, and $\delta_{c}\left(\delta_{f}\right.$ is zero because the fine mode particles were assumed to be spherical droplets), we compared the lidar-derived $k$ and $\delta_{p}$ with those computed for the aerosol optical model. Figure 3 presents the scatter diagram of $k$ as a function of $\delta_{p}$ obtained with the lidar and those computed by the model. We determined $k_{c}, \delta_{c}$, and $k_{f}$ in order to minimize the difference between the observed and modelled values. The lidar-derived values (solid diamonds in Fig. 3) fit to a line of the model for which $f_{c}$

Lidar measurements of Asian dust

T. Sakai et al.

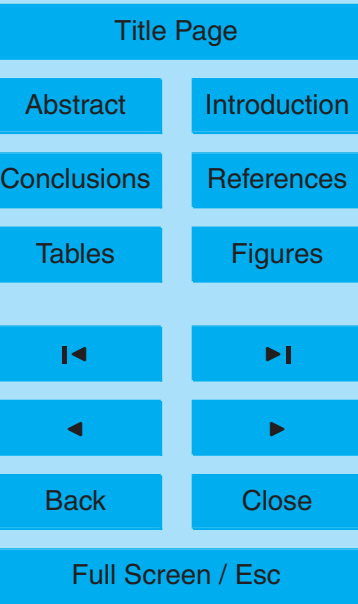

Printer-friendly Version

Interactive Discussion 
varied between 0 and 1 (thick solid line with open squares and numbers in Fig. 3). The $r_{g}^{N}$ varied from 0.02 to $0.4 \mu \mathrm{m}$ in steps of $0.02 \mu \mathrm{m}$ (thin line with open circles) for the fine mode and from 0.2 to $2.0 \mu \mathrm{m}$ in steps of $0.1 \mu \mathrm{m}$ for the coarse mode (thin line with open triangles).

$5 \quad$ We found that the lidar-derived values most closely fit the computed values when $r_{g}^{N}=0.1 \mu \mathrm{m}$ for the fine mode and $r_{g}^{N}=0.3 \mu \mathrm{m}$ for the coarse mode. These radii were consistent for the fine mode and a little smaller than the previously reported values obtained from the airborne optical particle counter measurements $(0.05$ to $0.1 \mu \mathrm{m}$ for the fine mode and 0.4 to $0.5 \mu \mathrm{m}$ or $1 \mu \mathrm{m}$ for the coarse mode) (Takamura et al., 1990;

10 Sakai et al, 2003; Matsuki et al., 2003), and consistent with those derived from the sky-radiometer measurements (Fig. 5). The optical properties computed for these two modes are given in Table 2. For comparison of the computed aerosol optical properties with those obtained from field experiments, Takamura et al. (1994) obtained $S_{p}$ of $61 \mathrm{sr}$ at $532 \mathrm{~nm}$ by use of the elastic lidar and sunphotometer data over Tsukuba in November 1990, when the Asian dust was rare. This value was close to our computed value for the fine mode. Murayama et al. (2004) obtained $S_{p} \sim 49 \mathrm{sr}$ at $355 \mathrm{~nm}, S_{p} \sim 43 \mathrm{sr}$ at $532 \mathrm{~nm}$, and $\delta_{p} \sim 20 \%$ for the Asian dust layers over Tokyo by use of the Raman and polarization lidar. Sakai et al. (2003) reported $S_{p}=47 \pm 18 \mathrm{sr}$ at $532 \mathrm{~nm}$ and $\delta_{p}=20 \pm 7 \%$ for the Asian dust layers over Tsukuba by the same technique. These values were close to or a little lower than our computed values for the coarse mode. It is necessary to determine the $S_{p}$ and $\delta_{p}$ of the Asian dust in a consistent manner such like laboratory experiment using a chamber.

For the estimation of $f_{c}$ averaged for the aerosol layers, Fig. 4 compares $k$ at the three wavelength pairs ( 355 to $532 \mathrm{~nm}, 532$ to $735 \mathrm{~nm}$, and 532 to $1064 \mathrm{~nm}$ ) and $\delta_{p}$ obtained with the lidar (solid symbols) and those calculated from the model (open symbols) for the aerosol layers observed for the two periods. The averaged $f_{c}$ values were 0.84 for the aerosol layer on 1 April (height range between 1.5 and $9.4 \mathrm{~km}$ ) and 0.17 on 19 October (height range between 1.5 and $4.7 \mathrm{~km}$ ).

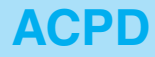

7, 10179-10203, 2007

Lidar measurements of Asian dust

T. Sakai et al.

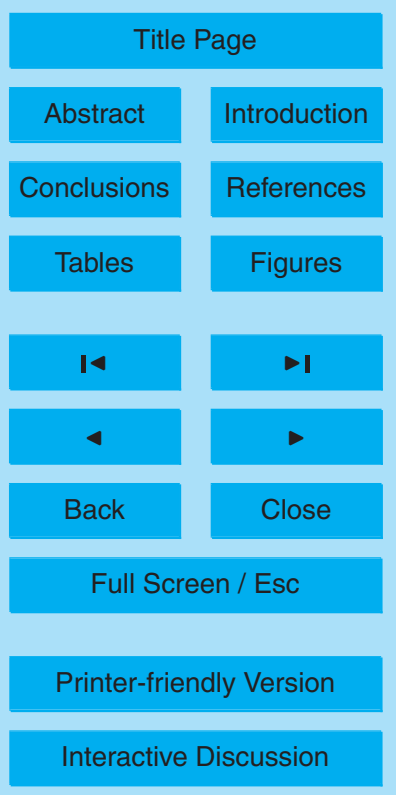


In order to determine $S_{p}$, we expressed $S_{p}$ in a similar manner to $\delta_{p}$ in Eq. (4) by

$S_{p}=\left(1-f_{c}\right) S_{f}+f_{c} S_{c}$

ACPD

By substituting $S_{f}$ and $S_{c}$ given in Table 2 and $f_{c}$ obtained from the lidar-derived $\delta_{p}$ profile (by Eq. 4) into Eq. (5), we obtained $S_{p}$ as a function of height. The obtained 5 values were used to compute the vertical profiles of $\beta_{p}$ at the four wavelengths. We used $\delta_{p}$ Eq. (4) instead of $k$ Eq. (5) to estimate $f_{c}$ because the measurement uncertainty in $\delta_{p}$ is lower than that in $k$. It was necessary to iterate the computation to derive these values $\left(\beta_{p}, \delta_{p}\right.$, and $\left.S_{p}\right)$ because they are mutually dependent. We found that $f_{c}$ ranged from 0.81 to 1 on 1 April and from 0.07 to 0.36 on 19 October (Fig. 3). The 10 corresponding $S_{p}$ values were $55-56,62,67-69$, and $71-78$ sr on 1 April and 50-52, $61,59-62$, and $45-55 \mathrm{sr}$ on 19 October at $355,532,735$, and $1064 \mathrm{~nm}$. It should be noted that $f_{c}$ decreased with height above an altitude of $3 \mathrm{~km}$ on 1 April (which could be expected from the decrease in $\delta_{p}$ with height in Fig. 1a), suggesting that the fraction of the coarse-mode particles decreased with height. This result was possibly due to the faster gravitational settling of the coarse particles than that of the fine particles.

Based on these results, we estimated the column particle concentration and size distribution. The column total particle number concentrations $(N)$ were estimated from $\beta_{p}$ and $f_{C}$ by

$N=N_{c}+N_{f}$,

20 where

$N_{c}=\int_{0}^{z_{\mathrm{top}}} f_{c}(z) \beta_{p}(z) d z / \frac{d \sigma_{c}}{d \Omega}$,

for the coarse mode and

$N_{f}=\int_{0}^{z_{\mathrm{top}}}\left[1-f_{c}(z)\right] \beta_{p}(z) d z / \frac{d \sigma_{f}}{d \Omega}$

Lidar measurements of Asian dust

T. Sakai et al.

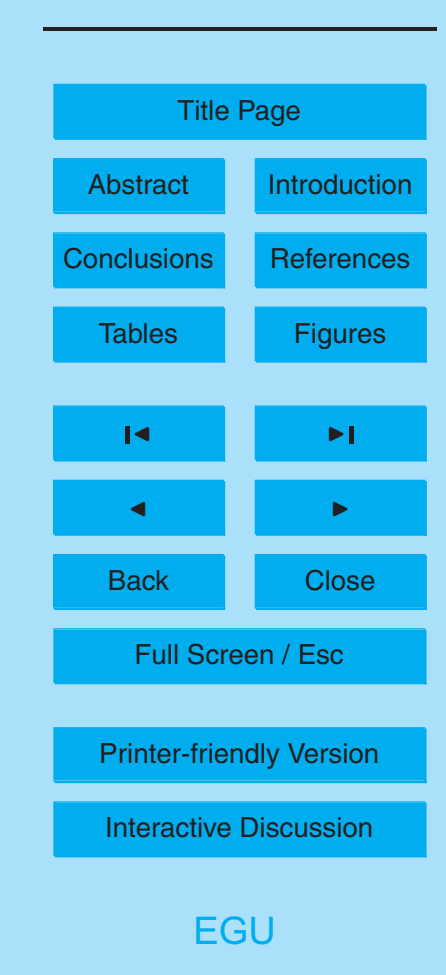


for the fine mode, where $\frac{d \sigma_{X}}{d \Omega}$ is the mean volume backscattering cross section of $x$ mode particles calculated from the model (Table 2). We used $\beta_{p}$ at $532 \mathrm{~nm}$ because the minimum level of the measurement was the lowest $(0.1 \mathrm{~km}$ in height) and the measurement uncertainty in the signal was the smallest among the four wavelengths.

5 We set $z_{\text {top }} 15 \mathrm{~km}$ and used the values at $0.1 \mathrm{~km}$ for the height integration between the ground and $0.1 \mathrm{~km}$. The column number concentrations were calculated to be $1.1 \times 10^{8} \mathrm{~cm}^{-2}\left(N_{C}=0.2 \times 10^{8} \mathrm{~cm}^{-2}\right.$ and $\left.N_{f}=0.9 \times 10^{8} \mathrm{~cm}^{-2}\right)$ on 1 April and $7.3 \times 10^{8} \mathrm{~cm}^{-2}$ $\left(N_{c}=2.4 \times 10^{6} \mathrm{~cm}^{-2}\right.$ and $\left.N_{f}=7.3 \times 10^{8} \mathrm{~cm}^{-2}\right)$ on 19 October.

\section{ACPD}

7, 10179-10203, 2007

\section{Lidar measurements} of Asian dust

T. Sakai et al.

\section{Comparison with sky-radiometer measurement}

10 Figure 5 plots the columnar volume size distributions for the two periods. It indicates the predominance of the coarse mode on 1 April and the fine mode on 19 October. For comparison of the size distribution, Fig. 5 also presents the size distributions derived from the sky-radiometer measurement $180 \mathrm{~m}$ east of the lidar at 06:40 JST on 1 April and 07:00 JST on 19 October 2006. The method for retrieving the 15 size distribution from the sky-radiometer measurement is described by Uchiyama et al. (2005a, b) and Kobayashi et al. (2006). The size distributions derived from the skyradiometer indicated a tri-modal distribution with volume mode radii $\left(r_{g}^{V}\right)$ of $0.25 \mu \mathrm{m}$, $1.16-1.69 \mu \mathrm{m}$, and $3.62 \mu \mathrm{m}$. The first and second mode radii were close to those estimated from the lidar data for the fine mode with $r_{g}^{V}=0.2 \mu \mathrm{m}$ (computed using the rela20 tion $\ln r_{g}^{V}=\ln r_{g}^{N}+\ln ^{2} \sigma_{g}$ ) and coarse mode with $r_{g}^{V}=1.3 \mu \mathrm{m}$. The third mode radius could not be captured by the lidar data because we assumed a bimodal distribution. The total volume concentrations $(V)$ were $0.19 \mu \mathrm{m}^{3} \mu \mathrm{m}^{-2}\left(V_{f}=0.01\right.$ and $\left.V_{c}=0.18 \mu \mathrm{m}^{3} \mu \mathrm{m}^{-2}\right)$ on 1 April and $0.12 \mu \mathrm{m}^{3} \mu \mathrm{m}^{-2}\left(V_{f}=0.1\right.$ and $\left.V_{c}=0.02 \mu \mathrm{m}^{3} \mu \mathrm{m}^{-2}\right)$, whereas those obtained from the sky-radiometer were $0.37 \mu \mathrm{m}^{3} \mu \mathrm{m}^{-2}\left(V_{f}=0.03\right.$ and $\left.V_{c}=0.34 \mu \mathrm{m}^{3} \mu \mathrm{m}^{-2}\right)$ on 1 25 April and $0.14 \mu \mathrm{m}^{3} \mu \mathrm{m}^{-2}\left(V_{f}=0.06\right.$ and $\left.V_{c}=0.08 \mu \mathrm{m}^{3} \mu \mathrm{m}^{-2}\right)$ on 19 October. The lidarderived $V$ were lower than those derived by the sky-radiometer by $48 \%$ on 1 April and

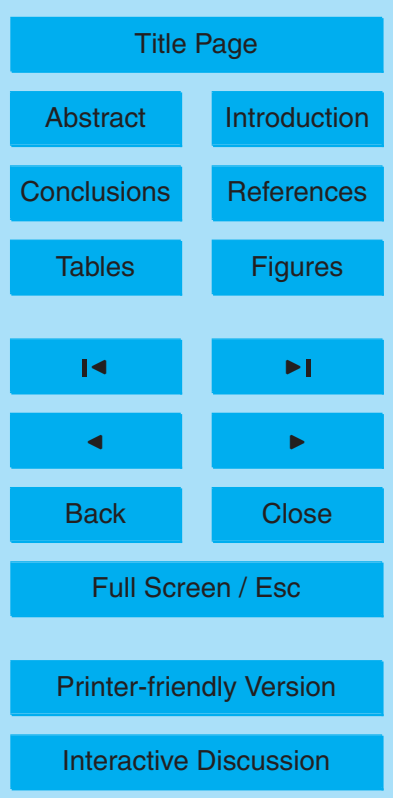

EGU 
$16 \%$ on 19 October. The reason for the difference between the lidar and sky-radiometer data is currently unresolved but is probably related to the uncertainty in the assumptions made for calculating the aerosol properties from the measurement data and the spatial and temporal variability of the aerosol properties between the two measure-

5 ments. The optical thicknesses $(\tau)$ at $532 \mathrm{~nm}$ derived from the lidar data were 0.44 on 1 April and 0.67 on 19 October, whereas those obtained from the sky-radiometer data were 0.50 on 1 April and 0.52 on 19 October, calculated by interpolating $\tau$ at 500 and $650 \mathrm{~nm}$. The lidar-derived $\tau$ were $12 \%$ lower than that obtained with the sky-radiometer on 1 April and $29 \%$ higher on 19 October.

More case studies are necessary to validate the method for estimating the particle size distribution from the lidar data because we used a simple model for calculating the aerosol optical properties. We assumed the two aerosol components of which particle shape, refractive index, and the size distribution shape ( $\sigma_{g}$ of the lognormal distribution) were constant over the height; only their proportion $\left(f_{c}\right)$ varied with height. Moreover, 15 the measurement data used in this study were taken for only the two periods when the transportation pathways of the air parcels were similar (westerly winds prevailed over the lidar site), so that potential source regions and the predominant aerosol constituents might also be similar. If the predominating aerosol constituents were different from this case study, the parameters $\left(k_{c}, \delta_{c}\right.$, and $\left.k_{f}\right)$ of the aerosol model should be modified. In addition, the lidar-derived values must be compared with those obtained with the in-situ aerosol instruments (e.g. particle counters) to validate the results.

\section{Conclusions}

The vertical profiles of aerosol backscattering coefficients and depolarization ratio were measured by use of multiwavelength and polarization lidar over Tsukuba, Japan, in

2006. The Asian dust layer between altitudes of 3 and $8.5 \mathrm{~km}$ on 1 April revealed $k=-0.1$ to 0.5 and $\delta_{p} \sim 25 \%$. The aerosol layer between 1.5 and $5 \mathrm{~km}$ on 19 October revealed $k=1.0$ to 1.6 and $\delta_{p}=1$ to $13 \%$. The values of $k$ and $\delta_{p}$ varied with height, and

Lidar measurements of Asian dust

T. Sakai et al.

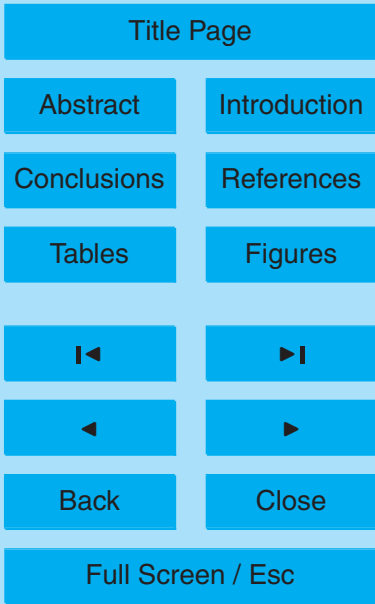

Printer-friendly Version

Interactive Discussion 
they were negatively correlated in those layers, suggesting that the proportion of the coarse nonspherical dust particles to the total particles varied with height. The fraction of the coarse particles in total backscattering was estimated to vary from 0.81 to 1 with an average of 0.84 on 1 April, and from 0.07 to 0.36 with an average of 0.17 on 19 5 October. The mode radii of these particles were estimated to be $0.3 \mu \mathrm{m}$ for the coarse mode and $0.1 \mu \mathrm{m}$ for the fine mode based on $k$ and $\delta_{p}$ values obtained with the lidar and the aerosol model. The column volume concentrations derived from the lidar were $0.19 \mu \mathrm{m}^{3} \mu \mathrm{m}^{-2}$ on 1 April and $0.12 \mu \mathrm{m}^{3} \mu \mathrm{m}^{-2}$ on 19 October. These concentrations were $48 \%$ lower than those derived from the sky-radiometer on 1 April and $16 \%$ lower 10 on 19 October. The optical thicknesses derived from the lidar were 0.44 on 1 April and 0.67 on 19 October, which were lower than that derived from the sky-radiometer by $12 \%$ on 1 April and higher by $29 \%$ on 19 October. The reason for the differences is not resolved but probably the incorrectness of assumptions of the aerosol model used for calculating the aerosol properties from the measured data and temporal and spatial variability of the aerosol properties between the measurements. Further case studies and comparisons with in-situ measurements are needed to validate the method for estimating the aerosol properties from the lidar measurement.

\section{References}

Ackermann, J.: The extinction-to-backscatter ratio of tropospheric aerosol: a numerical study, J. Atmos. Ocean. Tech., 15, 1043-1050, 1998.

Ansmann A., Wagner, F., Müller, D., Althausen, D., Herber, A., von Hoyningen-Huene, W., and Wandinger, U.: European pollution outbreaks during ACE 2: Optical particle properties inferred from multiwavelength lidar and star-Sun photometry, J. Geophys. Res., 107(D15), 4259, doi:10.1029/2001JD001109, 2002.

25 Aoki, T., Tanaka, T. Y., Uchiyama, A., Chiba, M., Mikami, M., Yabuki, S., and Key, J. R.: Sensitivity experiments of direct radiative forcing caused by mineral dust simulated with a chemical transport model, J. Meteorol. Soc. Jpn., 83A, 315-331, 2005.

Arimoto, R., Kim, Y. J., Kim, Y. P., Quinn, P. K., Bates, T. S., Anderson, T. L., Gong, S., Uno,

Lidar measurements of Asian dust

T. Sakai et al.

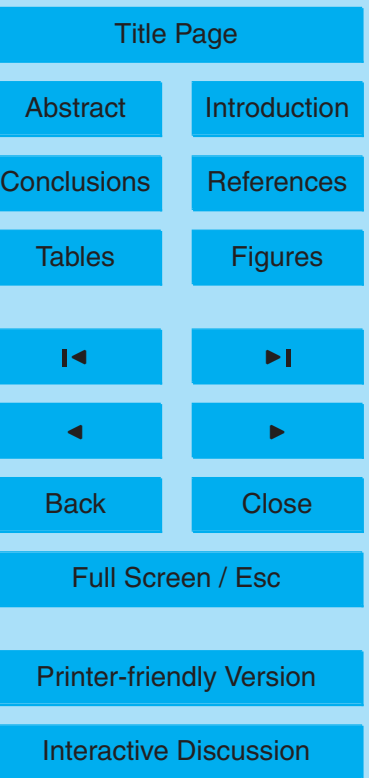


I., Chin, M., Huebert, B. J., Clarke, A. D., Shinozuka, Y., Weber, R. J., Anderson, J. R., Guazzotti, S. A., Sullivan, R. C., Sodeman, D. A., Prather, K. A., and Sokolik, I. N.: Characterization of Asian Dust during ACE-Asia, Global and Planet. Change, 52, 23-56, 2006.

Bohren, C.F. and D. R. Huffman: Absorption and Scattering of Light by Small Particles Wiley, New York, 1983.

Dubovik, O. and King, M. D.: A flexible inversion algorithm for retrieval of aerosol properties from sun and sky radiance measurements, J. Geophys. Res., 105, 20 673-20 696, 2000.

Duce, R. A.: Sources, distributions, and fluxes of mineral aerosols and their relationship to climate, in Aerosol Forcing of Climate, edited by: Charlson, R. J. and Heitzenberg, J., John 10 Wiley, New York, pp.43-72, 1995.

Fernald, F. G., Herman, B. M., and Reagan, J. A.: Determination of aerosol height distributions by lidar, J. Appl. Meteorol., 11, 482-489, 1972.

Huebert, B. J., Bates, T., Russell, P. B., Shi, G. Y., Kim, Y. J., Kawamura, K., Carmichael, G., and Nakajima, T.: An overview of ACE-Asia: Strategies for quantifying the relationships between Asian aerosols and their climatic impacts, J. Geophys. Res., 108(D23), 8633, 10.1029/2003JD003550, 2003.

Ismail, S., Browell, E. V., Ferrare, R. A., Kooi, S. A., Clayton, M. B., Brackett, V. G., and Russell, P. B.: LASE measurements of aerosol and water vapor profiles during TARFOX, J. Geophys. Res., 105, 9903-9916, 2000.

20 Isono, K., Komabayashi, M., and Ono, A.: The nature and the origin of ice nuclei in the atmosphere, J. Meteorol. Soc. Jpn., 37, 211-233, 1959.

Iwasaka, Y., Yamato, M., Imasu, R., and Ono, A.: Transport of Asian dust (KOSA) particles; importance of weak KOSA events on the geochemical cycle of soil particles, Tellus, 40B, 494-503, 1988.

Kalashnikova, O. V. and Sokolik, I. N.: Modelling the radiative properties of nonspherical soilderived mineral aerosols, J. Quant. Spectrosc. Ra., 87, 137-166, 2004.

Kobayashi, E., Uchiyama, A., Yamazaki, A., and Matsuse, K.: Application of the statistical optimization method to the inversion algorithm for analyzing aerosol optical properties from sun and sly radiance measurement, J. Meteorol. Soc. Jpn., 84, 1047-1062, 2006.

30 Liao, H. and Seinfeld, J. H.: Effect of clouds on direct aerosol radiative forcing on climate, J. Geophys. Res., 103, 3781-3788, 1998.

Müller, D., Wandinger, U., and Ansmann, A.: Microphysical particle parameters from extinction and backscatter lidar data by inversion with regularization: Theory, Appl. Optic, 38, 2346-

Lidar measurements of Asian dust

T. Sakai et al.

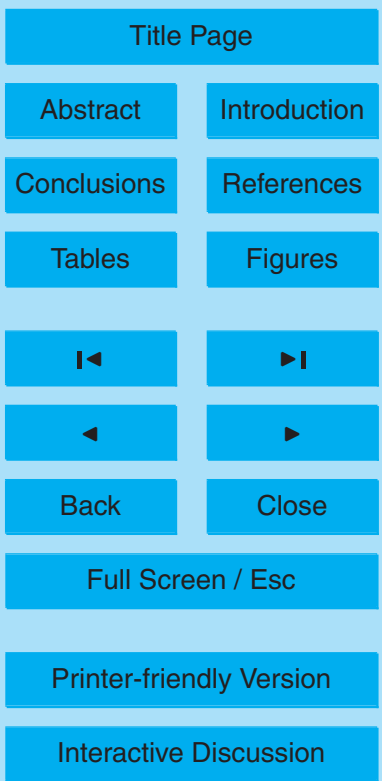


2357, 1999.

Müller, D., Wagner, F., Wandinger, U., Ansmann, A., Wendisch, M., Althausen, D., and von Hoyningen-Huene, W.: Microphysical particle parameters from extinction and backscatter lidar data by inversion with regularization: Experiment, Appl. Optic, 39, 1879-1892, 2000.

5 Mano, Y.: Exact solution of electromagnetic scattering by a three-dimensional hexagonal ice column obtained with the boundary-element method, Appl. Optic, 39, 5541-5546, 2000.

Matsuki, A., Iwasaka, Y., Osada, K., Matsunaga, K., Kido, M., Inomata, Y., Trochkine, D., Nishita, C., Nezuka, T., Sakai, T., Zhang, D., Kwon, S.-A.: Seasonal dependence of the long-range transport and vertical distribution of free tropospheric aerosols over east Asia: On the basis of aircraft and lidar measurements and isentropic trajectory analysis, J. Geophys. Res., 108(D23), 8663, doi:10.1029/2002JD003266, 2003.

Mikami, M., Shi, G.-Y., Uno, I., Yabuki, S., Iwasaka, Y., Yasui, M., Aoki, T., Tanaka, T. Y., Kurosaki, Y., Masuda, K., Uchiyama, A., Matsuki, A., Sakai, T., Takemi, T., Nakawo, M., Seino, N., Ishizuka, M., Satake, S., Fujita, K., Hara, Y., Kai, K., Kanayama, S., Hayashi, M., Du, M., Kanai, Y., Yamada, Y., Zhang, X.-Y., Shen, Z. , Zhou, H., Abe, O., Nagai, T., Tsutsumi, Y., Chiba, M., and Suzuki, J.: Aeolian Dust Experiment on Climate Impact: An Overview of Japan-China Joint Project ADEC, Global Planet. Change, 52, 142-172, doi:10.1016/j.gloplacha.2006.03.001, 2006.

Murayama, T., Müller, D., Wada, K., Shimizu, A., Sekiguchi, M., and Tsukamoto, T.: Characterization of Asian dust and Siberian smoke with multi-wavelength Raman lidar over Tokyo, Japan in spring 2003, Geophys. Res. Lett., 31, L23103, doi:10.1029/2004GL021105, 2004.

Okada, K., Heintzenberg, J., Kai, K., and Qin, Y.: Shape of atmospheric mineral particles collected in three Chinese arid-regions, Geophys. Res. Lett., 28(16), 3123-3126, 2001.

Quijano, A. L., Sokolik, I. N., and Toon, O. B.: Radiative heating rates and direct radiative 25 forcing by mineral dust in cloudy atmospheric conditions, J. Geophys. Res., 105, 1220712220, doi:10.1029/2000JD900047, 2000.

Russell, P. B., Swissler, T. J., and McCormick, M. P.: Methodology for error analysis and simulation of lidar aerosol measurements, Appl. Optic, 18, 3783-3797, 1979.

Russell, P. B., Morley, B. M., Livingston, J. M., Grams, G. W., and Patterson, E. M.: Orbiting lidar simulations. 1: Aerosol and cloud measurements by an independent-wavelength technique, Appl. Optic, 21, 1541-1553, 1982.

Sakai, T., Shibata, T., Kwon, S. A., Kim, Y. S., Tamura, K., and Iwasaka, Y.: Free tropospheric aerosol backscatter, depolarization ratio and relative humidity measured with the Raman 
lidar at Nagoya in 1994-1997: contributions of aerosols from the Asian continent and the Pacific Ocean, Atmos. Environ., 34, 431-442, 2000.

Sakai, T., Nagai, T., Nakazato, M., Mano, Y., and Matsumura, T.: Ice clouds and Asian dust studied with lidar measurements of particle extinction-to-backscatter ratio, particle depolar-

5 ization, and water vapor mixing ration over Tsukuba, Appl. Optic, 42, 7103-7116, 2003.

Sakai, T., Shibata, T., Hara, K., Kido, M., Osada, K., Hayashi, M., Matsunaga, K., and Iwasaka, Y.: Raman lidar and aircraft measurements of tropospheric aerosol particles during the Asian dust event over central Japan: Case study on 23 April 1996, J. Geophys. Res., 108(D12), 4349, 10.1029/2002JD003150, 2003.

10 Sassen, K.: Lidar backscatter depolarization technique for cloud and aerosol research, in Light Scattering by Nonspherical Particles: Theory, Measurements, and Applications, edited by: Mishchenko, M. L., Hovenier, J. W., and Travis, L. D., pp.393-416, Academic Press, San Diego, 2000.

Shi, G., Wang, H., Wang, B., Li, W., Gong, S., Zhao, T., and Aoki, T.: Sensitivity experiments 15 on the effects of optical properties of dust aerosols on their radiative forcing under clear sky condition, J. Meteorol. Soc. Jpn., 83A, 333-346, 2005.

Sokolik, I. N. and Toon, O. B.: Incorporation of mineralogical composition into models of the radiative properties of mineral aerosol from UV to IR wavelengths, J. Geophys. Res., 104, 9423-9444, 1999.

20 Sugimoto, N. and Lee, C. H.: Characteristics of dust aerosols inferred from lidar depolarization measurements at two wavelengths, Appl. Optic, 45, 7468-7474, 2006.

Takamura, T., Sasano, Y., and Hayasaka, T.: Troposheric aerosol optical properties derived from lidar, sun photometer, and optical particle counter measurements, Appl. Optic, 33, 7132-7140, 1994.

Takamura, T. and Sasano, Y.: Aerosol optical properties inferred from simultaneous lidar, aerosol-counter, and sunphotometer measurements, J. Meteorol. Soc. Jpn., 68, 729-739, 1990.

Tang, I. N. and Munkelwitz, H. R.: Water activities, densities, and refractive indices of aqueous sulfates and sodium nitrate droplets of atmospheric importance, J. Geophys. Res., 99, $30 \quad$ 18801-18 808, 1994.

Uchiyama, A., Yamazaki, A., Togawa, H., and Asano, J.: Characteristics of Asian dust observed by sky-radiometer in the Intense Observation Period 1 (IOP1), J. Meteorol. Soc. Jpn., 83A, 291-305, 2005a.

Lidar measurements of Asian dust

T. Sakai et al.

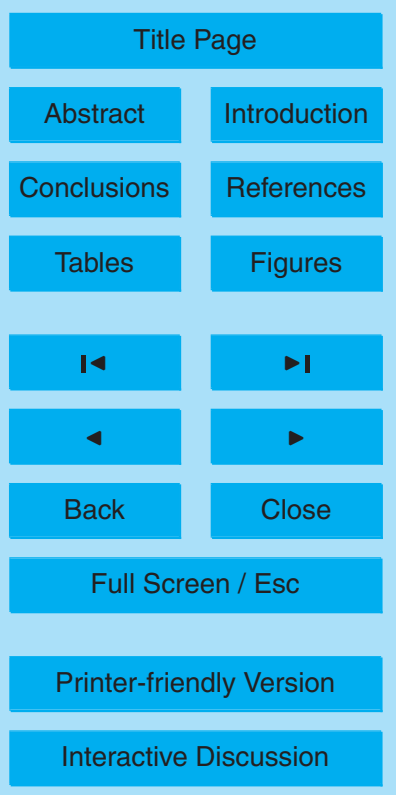

EGU 
Uchiyama, A., Yamazaki, A., Togawa, H., Asano, J., and Shi, G.: Single scattering albedo of aeolian dust as inferred from sky-radiometer and in situ ground based measurement, SOLA, 1, 209-212, 2005b.

Veselovskii, I., Kolgotin, A., Müller, D., and Whiteman, D. N.: Information content of multiwavelength lidar data with respect to microphysical particle properties derived from eigenvalue analysis, Appl. Optic, 44, 5292-5303, 2005.

Yamagata, S., Kuroda, T., Zaima, T., Murao, N., Ohta, S., Fujiyoshi, Y., Harimaya, T., Yamada, T., Izumi, K., Fukuyama, T., and Utiyama, M.: Mineral particles in cloud droplets produced in an artificial cloud experimental system (ACES), Aerosol Sci. Tech., 38, 293-299, 2004.

\section{ACPD}

7, 10179-10203, 2007

\section{Lidar measurements} of Asian dust

T. Sakai et al.

Title Page

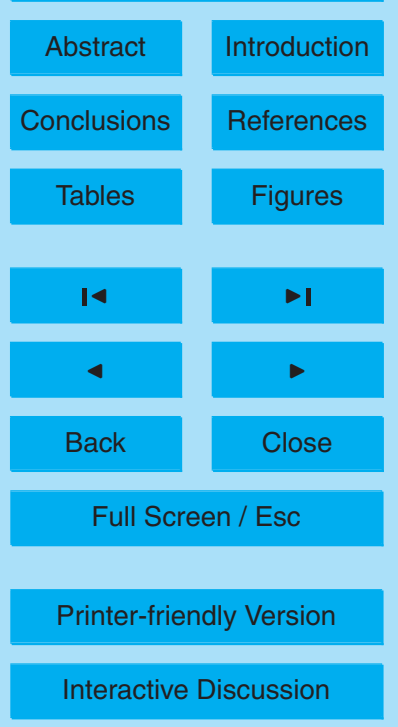




\section{ACPD}

7, 10179-10203, 2007

Table 1. Specification of lidar used in this study.

\section{Lidar measurements of Asian dust}

\begin{tabular}{|c|c|c|c|c|c|}
\hline Lidar type & \multicolumn{4}{|c|}{ Multiwavelength lidar } & Polarization lidar \\
\hline \multicolumn{6}{|l|}{ Transmitter } \\
\hline Wavelength (nm) & 355 & 532 & 1064 & 735 & 532 \\
\hline $\begin{array}{l}\text { Laser type } \\
\text { (Continuum, Inc.) }\end{array}$ & \multicolumn{2}{|c|}{ Nd:YAG (PL8020) } & $\begin{array}{l}\text { Nd:YAG } \\
\text { (YG581C) }\end{array}$ & $\begin{array}{l}\text { ND:YAG-pumped } \\
\text { Dye (TDL60) }\end{array}$ & $\begin{array}{l}\text { Nd:YAG } \\
\text { (SL2) }\end{array}$ \\
\hline Repetition rate $(\mathrm{Hz})$ & 20 & & 20 & 10 & 10 \\
\hline Energy/pulse (mJ) & 80 & 40 & 550 & 16 & 300 \\
\hline $\begin{array}{l}\text { Beam divergence (mrad) } \\
\text { Receiver }\end{array}$ & 0.125 & 0.125 & 0.125 & 2.0 & 0.2 \\
\hline Telescope type & \multicolumn{3}{|c|}{ Nasmyth } & Schmidt-Cassegrain & Schmidt-Cassegrain \\
\hline Diameter (m) & \multicolumn{3}{|l|}{0.5} & 0.35 & $0.2,0.4$ \\
\hline Field of view (mrad) & \multicolumn{3}{|l|}{3.0} & 2.2 & $3.0,2.0$ \\
\hline Detection wavelength (nm) & 355 & 532 & 1064 & 735 & 532 \\
\hline Detection species & Elastic & Elastic & Elastic & Elastic & Elastic and Polarization \\
\hline Filter bandwidth (nm) & 0.50 & 0.57 & 0.46 & 3.00 & 0.50 \\
\hline $\begin{array}{l}\text { Photomultiplier tubes } \\
\text { (Hamamatsu Photonics) }\end{array}$ & R1332 & $\mathrm{R} 1332$ & R3236-01 & $\mathrm{R} 1333$ & R3234-01 \\
\hline Detection mode* & \multicolumn{3}{|c|}{$P C$ and $A / D$} & $P C$ and $A / D$ & $P C$ and $A / D$ \\
\hline Range resolution (m) & \multicolumn{3}{|c|}{7.5} & 7.5 & 7.5 \\
\hline Temporal resolution (min) & \multicolumn{3}{|l|}{1.5} & 3 & 3 \\
\hline
\end{tabular}

T. Sakai et al.

* PC: Photon counting. A/D: analog-to-digital conversion.

Title Page

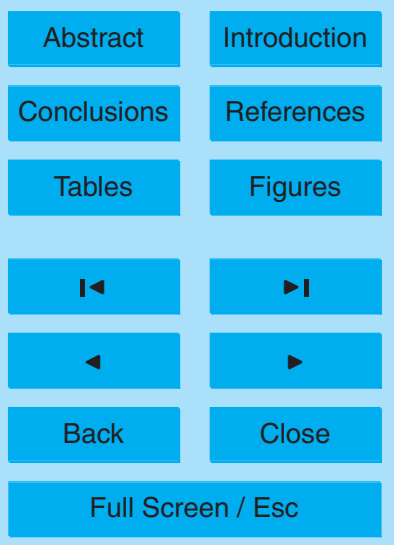

Printer-friendly Version

Interactive Discussion 


\section{ACPD}

7, 10179-10203, 2007

\section{Lidar measurements} of Asian dust

Table 2. Optical properties computed for the aerosol model.

\section{T. Sakai et al.}

\begin{tabular}{|c|c|c|c|c|c|c|c|c|}
\hline Mode & \multicolumn{4}{|c|}{ Fine } & \multicolumn{4}{|c|}{ Coarse } \\
\hline Species & \multicolumn{4}{|c|}{ ammonium bisulphate } & \multicolumn{4}{|c|}{ mineral dust } \\
\hline Refractive index & \multicolumn{4}{|c|}{$1.46+0 \mathrm{i}$} & \multicolumn{4}{|c|}{$1.5+0.001 i$} \\
\hline \multicolumn{9}{|l|}{ Size distribution } \\
\hline geometric mean radius $(\mu \mathrm{m})^{\star}$ & \multirow{2}{*}{\multicolumn{4}{|c|}{$\begin{array}{c}0.1 \\
1.66\end{array}$}} & \multicolumn{4}{|c|}{0.3} \\
\hline geometric standard deviation & & & & & \multirow{2}{*}{\multicolumn{4}{|c|}{$\begin{array}{c}2 \\
\text { triaxial ellipsoid }\end{array}$}} \\
\hline Shape & \multicolumn{4}{|c|}{ sphere } & & & & \\
\hline Wavelength (nm) & 355 & 532 & 735 & 1064 & 355 & 532 & 735 & 1064 \\
\hline$k(532 \mathrm{~nm}-\lambda)$ & 1.55 & - & 1.47 & 1.38 & -0.15 & - & 0.22 & 0.38 \\
\hline$\delta_{p}(\%)$ & - & 0 & - & - & - & 27 & - & - \\
\hline$S_{p}(\mathrm{sr})$ & 50 & 61 & 58 & 42 & 56 & 62 & 69 & 78 \\
\hline $\mathrm{d} \sigma / \mathrm{d} \Omega\left(10^{-14} \mathrm{~m}^{2} \mathrm{sr}^{-1}\right)$ & 1.2 & 0.5 & 0.6 & 0.4 & 3.6 & 3.8 & 3.6 & 3.0 \\
\hline
\end{tabular}

\section{Title Page}

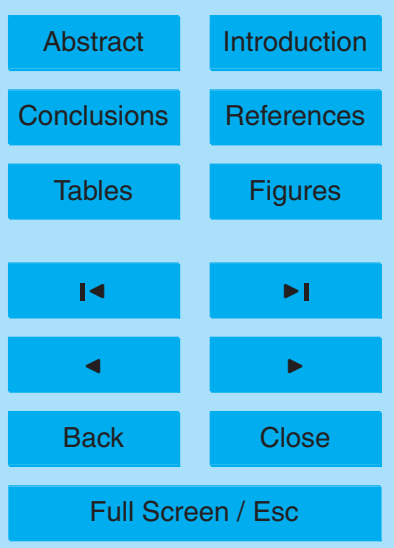

* Values were estimated from the lidar measurements (see Sect. 3).

** Length-to-height ratio was 1.4 , and height-to-width ratio ranged from 0.2 to 1.0 , based on microscopic measurement of Asian dust by Okada et al. (2001). 

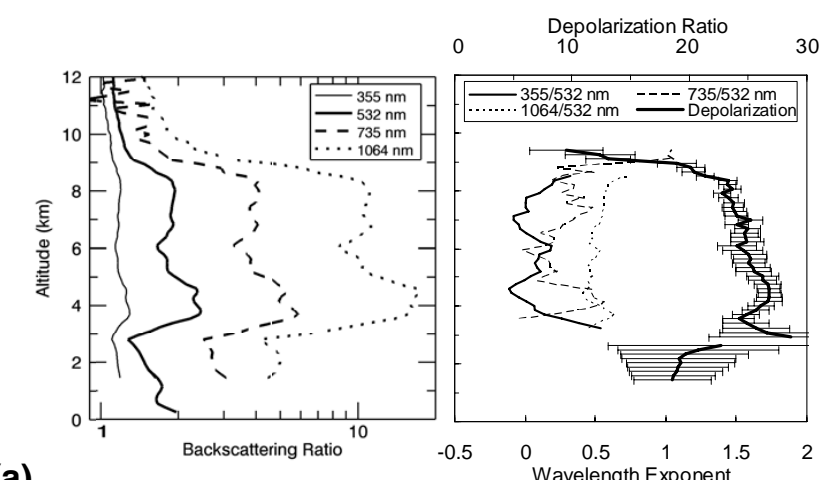

\section{ACPD}

(a)
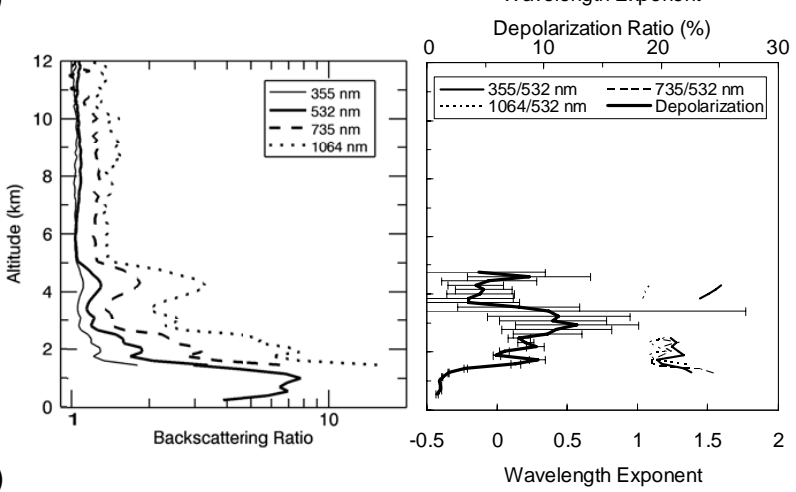

(b)

Fig. 1. Vertical distribution of the particle optical properties that were obtained with the lidar for the period 00:01-05:03 JST on 1 April 2006 (a) and 02:01-06:45 JST on 19 October 2006 (b) over Tsukuba. The left panels show the backscattering ratios at wavelengths of $355,532,735$, and $1064 \mathrm{~nm}$. The right panels show the wavelength exponent of the backscattering coefficients and the particle depolarization ratio at $532 \mathrm{~nm}$.

\section{Lidar measurements} of Asian dust

\section{T. Sakai et al.}

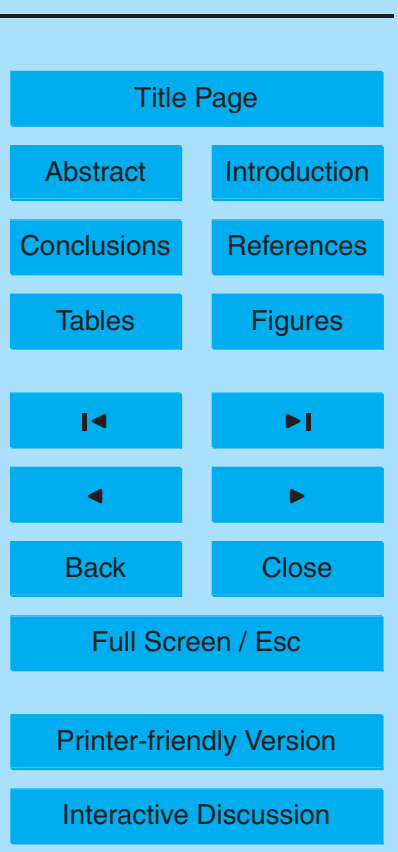




\section{ACPD}

\section{7, 10179-10203, 2007}

5-day isentropic backward trajectories on 1 April 2:00 JST

(a)
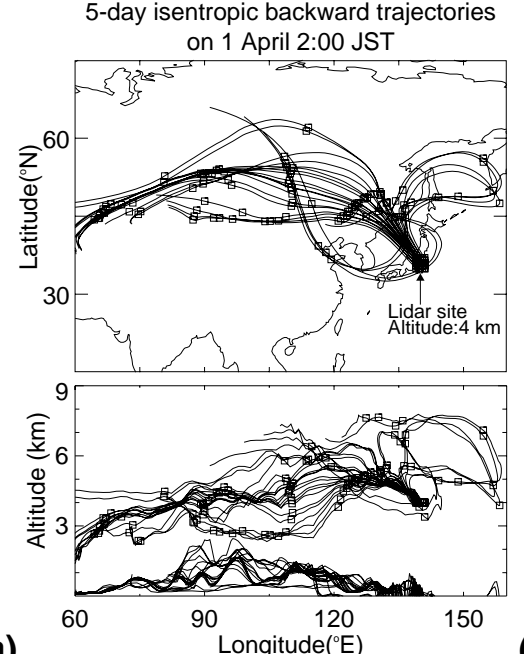

(b)

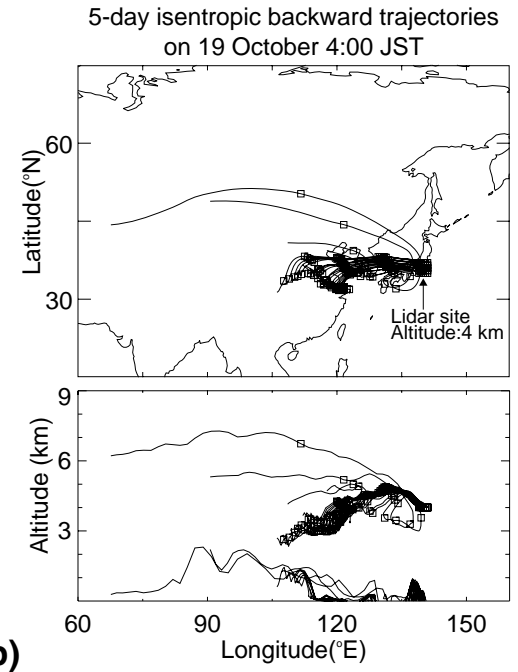

Fig. 2. Clustered isentropic backward trajectories of the air parcels arriving over the lidar site at an altitude of $4 \mathrm{~km}$ on 1 April (a) and 19 October (b) in 2006. Symbols are plotted at 24-h intervals. The lowermost lines in the vertical cross section show the land elevations.

\section{Lidar measurements} of Asian dust

\section{T. Sakai et al.}

Title Page

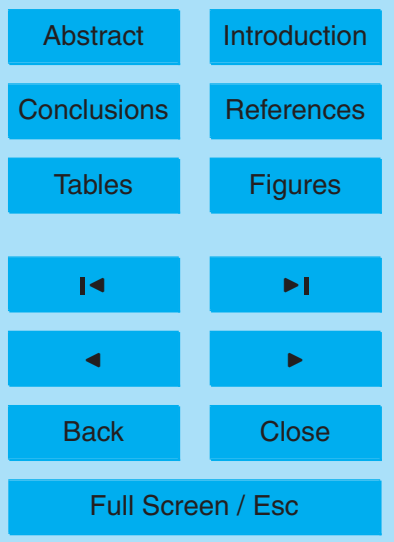

Printer-friendly Version

Interactive Discussion 


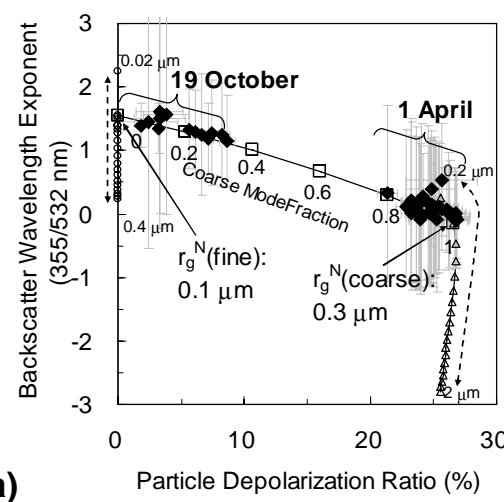

(a)

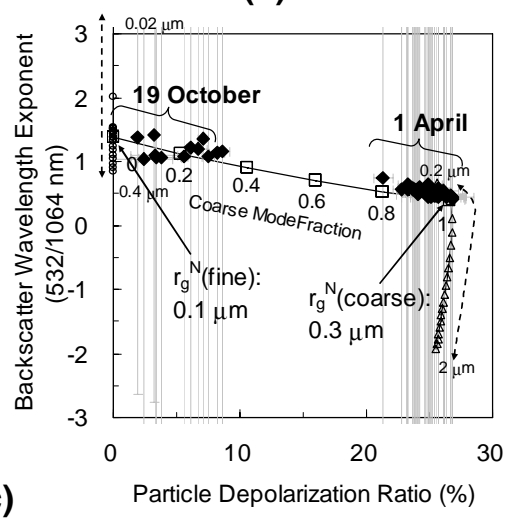

(c) Particle Depolarization Ratio (\%)

Fig. 3. Scatter diagrams of wavelength exponent of backscattering coefficients as a function of depolarization ratio. The wavelength exponents were between 355 and $532 \mathrm{~nm}$ (a), 532 and $735 \mathrm{~nm}$ (b), and 532 and $1064 \mathrm{~nm}$ (c). Solid diamonds indicate the measured values. Open symbols (circles for the fine mode and triangles for the coarse mode) denote the computed values for which the mode radii varied from 0.02 to $0.4 \mu \mathrm{m}$ and 0.2 to $2.0 \mu \mathrm{m}$. Numbers ( 0 to 1$)$ on a solid line with open squares represent the ratio of coarse to total particles; the mode radii was $0.3 \mu \mathrm{m}$ for the coarse mode and $0.1 \mu \mathrm{m}$ for the fine mode.

\section{ACPD}

7, 10179-10203, 2007

\section{Lidar measurements} of Asian dust

\section{T. Sakai et al.}

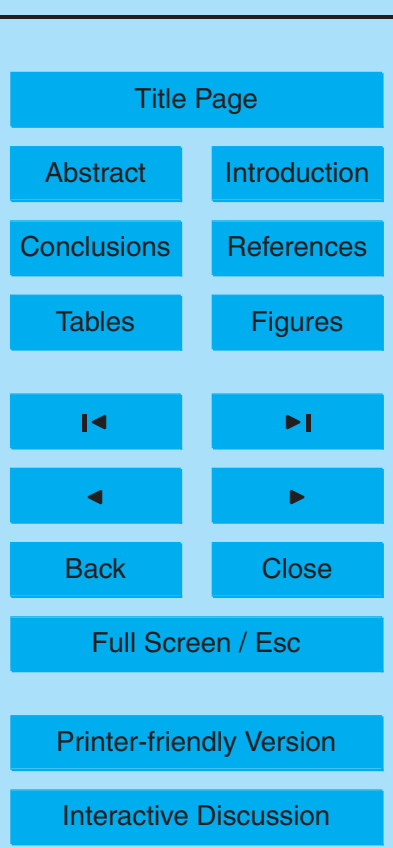




\section{ACPD}

7, 10179-10203, 2007

\section{Lidar measurements} of Asian dust

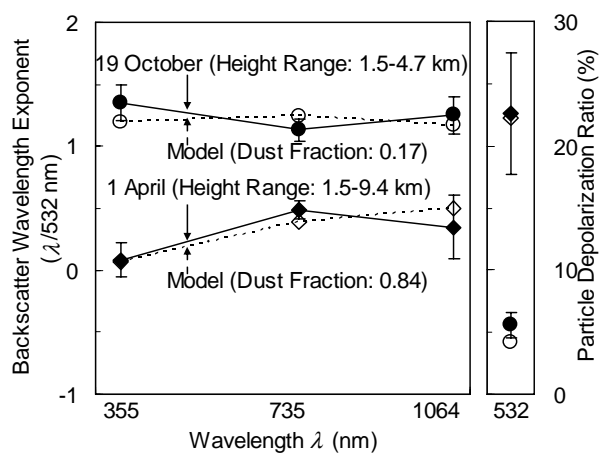

\section{T. Sakai et al.}

Title Page

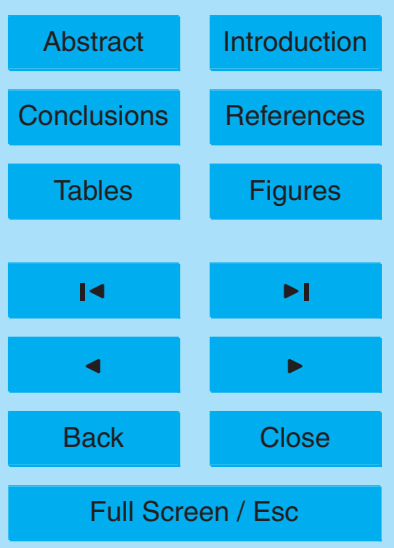

Fig. 4. Comparison of wavelength exponent of backscattering coefficients between 355 and $1064 \mathrm{~nm}$ (left panel) and particle depolarization ratio (right panel) between the lidar-derived values and the models. Solid symbols indicate the lidar-derived values averaged for heights of 1.5 to $9.4 \mathrm{~km}$ on 1 April (diamonds) and of 1.5 to $4.7 \mathrm{~km}$ on 19 October (circles). Open symbols denote the values obtained using the model, assuming the dust fraction of 0.84 (diamonds) and 0.17 (circles) that fit the measurements. The error bar indicates the standard deviation in the height ranges.
Printer-friendly Version

Interactive Discussion

\section{Full Screen / Esc}




\section{ACPD}

7, 10179-10203, 2007

\section{Lidar measurements} of Asian dust
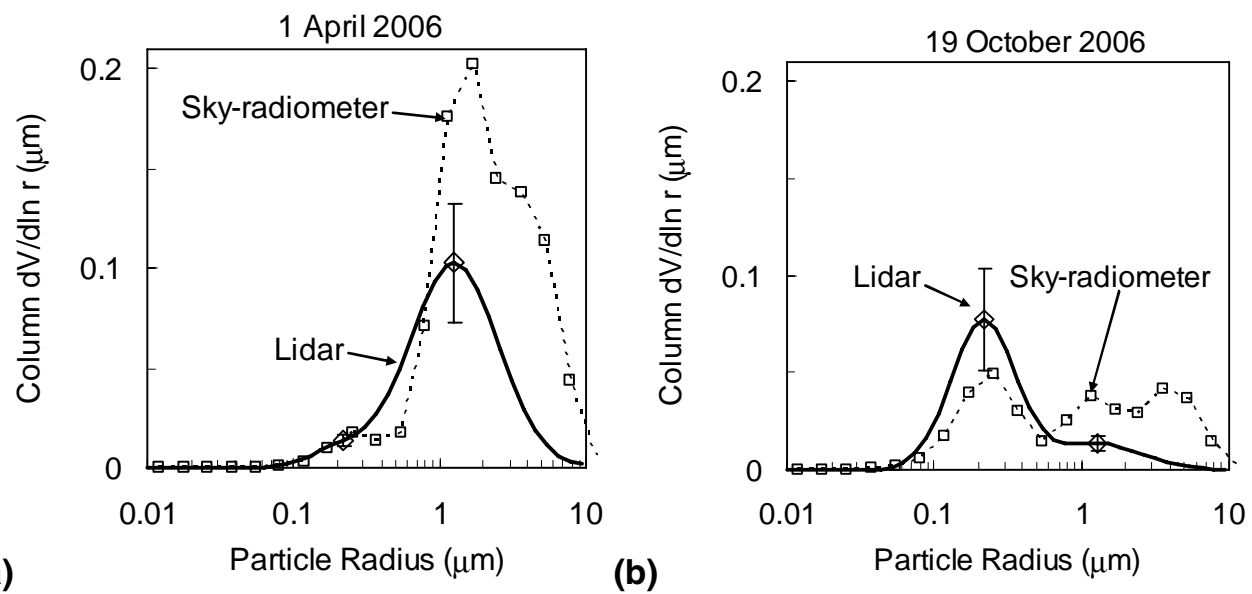

\section{T. Sakai et al.}

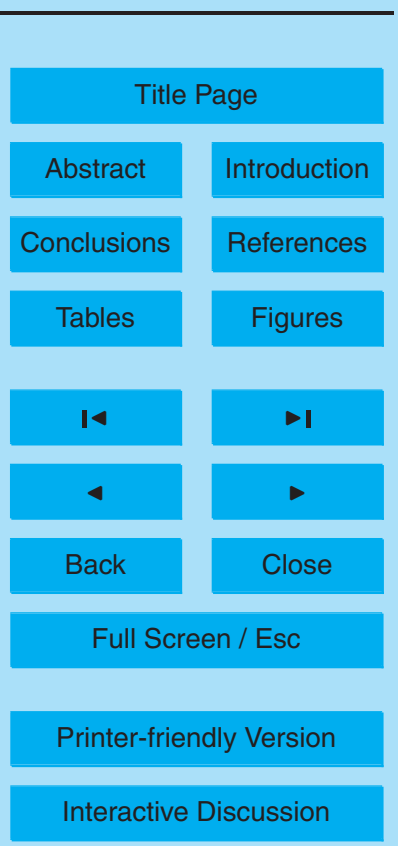

